American Journal of Art and Design
2021; 6(2): 55-59
http://www.sciencepublishinggroup.com/j/ajad
doi: $10.11648 / j$. ajad.20210602.13
ISSN: 2578-7799 (Print); ISSN: 2578-7802 (Online)

\title{
Design in the Spectral Music of Tristan Murail
}

\author{
Ana Szilagyi \\ Department of Instrumental and Vocal Pedagogy, Richard Wagner Conservatory, Vienna, Austria \\ Email address: \\ anaszilagyi71@gmail.com

\section{To cite this article:} \\ Ana Szilagyi. Design in the Spectral Music of Tristan Murail. American Journal of Art and Design. Vol. 6, No. 2, 2021, pp. 55-59. \\ doi: $10.11648 /$ j.ajad.20210602.13
}

Received: April 28, 2021; Accepted: May 31, 2021; Published: June 15, 2021

\begin{abstract}
This paper wants to highlight the creation process in the spectral music of Tristan Murail that supposes a special sound design. The spectral music uses the sound spectrum, i.e. the sound components (overtones) as material that give to a sound its timbre. The spectrum is based on the frequencies, which can be calculated with the computer. The aim of this paper is to describe some aspects of the work of Tristan Murail, which are in connection with the design, notions that himself uses describing his compositions, as material, models, modeling, object, process. The material is the sonority itself. The models are the technological ones taken from the electronic music as echo, reverberation, frequency modulation, etc. and translated in the instrumental (or/and electronic) music. After the analysis of a sound, which is decomposed in sine waves, follows the sound modeling through recombining the sound components, doing distortions or other effects borrowed from the electronic music. In this way new sounds are synthesized, which can be seen as more complex and sophisticated objects. The composer deals with an amount of sounds, therefore the computer is important in the compositional process to calculate a great number of sound combinations. The compositional conception of Murail has changed with the development of the computer technology and music informatics. In this way, I should mention the role of computer in the sound design of Murail. The process is an integral part both of the composing and of the composition. The composition evolves over time as the sound does: it is in a continuous changing. Sound evolution is also a model for Murail to shape the form of his compositions.
\end{abstract}

Keywords: Harmonic Series, Harmonic Spectrum, Overtones, Timbre, Frequency, Analysis-Synthesis

\section{Introduction}

The composer Tristan Murail (*1947) is an important exponent of the Spectral Music (Musique Spectrale), a composition technique that appeared in the 70 s in France, which has used the harmonic series of a sound, its harmonic or inharmonic components (partials). Tristan Murail created 1973 with Gérard Grisey (1946-1988), Michaël Levinas (*1949), Hugues Dufourt (*1943) and Roger Tessier (*1939) "l'Ensemble Itinéraire", which gave them the opportunity to perform their spectral works and to experiment new play techniques.

The spectral music is based on the sound timbre, one of the sound parameters besides pitch, duration, and amplitude, which gives the color in the music. Components of timbre are analyzed: harmonicity, inharmonicity, noise, roughness (microfluctuations of frequency or amplitude), brightness, attack of the overtones (synchronous or not). With the help of computer programs these components can be separated, distorted, recombined and synthesized, getting similar timbre in the instrumental or electroacoustic music. Through Fourier's Theorem any sound can be decomposed in simple units named sine waves. The most common method used by the spectralists is the additive synthesis, which consists in building up complex sounds recombining sine waves. However, the result is not satisfactory. As Joshua Fineberg writes, for recreating a sound one needs an amount of components and data to give it dynamics, in order to avoid simplicity and statics [1]. Francois Rose also notes the difference between the model and the realization in the fact that in the spectral music "each component is played by a musical instrument rather than being a sine tone." [2].

The analysis of the inner sound was possible because of the technology progress. Thus, Murail's concept and design evolved parallel with the technology and music informatics. The increasing of the velocity and precision in manipulating the sounds with the computer leads him to develop new acoustic models, taken from the electronic music and translated into the instrumental one, as frequency and 
amplitude modulation, ring modulation, echo, reverberation, phase shifting, filtering, distortion, etc. Oliver Schneller writes that in the spectral music the inner complex life of a sound serves as basis of the whole design of a composition [3].

In the following paragraphs it will be shown the sound design of Murail, taking in discussion his conception, methodology, where the computer plays an important role, referring to some compositions of him. The analysissynthesis process, that is central in his work, involves other aspects, characteristic of the design, notions which himself has spoken about, as object, model, process, technology or productivity.

\section{Analysis-Synthesis}

Murail had in 1980 the opportunity to attend computer courses at the famous IRCAM (Institut de Recherche et Coordination Acoustique/Musique) at Centre Pompidou in Paris. He was interested in the inner sound. The overtones (or harmonics) of a fundamental tone could be calculated without computer - until a degree - as its integer multiplies, but the formants, i.e. the overtones that are louder as well as the degree of noise that makes the timbre of which instrument unique can be found out only by the computer. Murail wanted to have these details, so he was content that the musicologist and composer David Wessel, who was working there, recorded samples of all the orchestra instruments, where he analyzed all the sounds and described them precisely [4]. Further, Murail composed Désintégrations (1982-1983) for 17 instruments and electronics, commissioned by IRCAM. The connection between the electronic and the instrumental sounds was assured by the transform of the sounds analyses [4]. Interested in the transforming of the piano sound, he chose some of its overtones, did some combinations and after that raised the first overtone, so the others overtones were raised in proportion. In this way he got a distortion. In the synthesis he recreated the piano sound putting its frequencies together with and without harmonic distortion [4].

Later IRCAM experimented new technologies that were able to follow the evolution of the partials over time. It was a difference regarding the former, static spectral analyses, because one could see obviously the changing of each partial over time. In L'Esprit des dunes (1994) for ensemble and electronics Murail analyzed and modified the sounds, treating them in a compositional way, so that the synthesis sounds gave the impression they were more dynamic [5]. The material used was from Asia: Tibetan trumpet and diaphonic (two voices) Mongol song. Analyzing the first 40 partials of the Tibetan trumpet, Murail observed that the frequencies of all the partials are lightly compressed $(-2.5 \%)$ [Table 1], fact that gives an inharmonic coloration to the spectrum [6]. Philippe Lalitte presented a table with the differences between the frequency and the amplitude of the first 10 partials of the Tibetan trumpet [6]:

Table 1. Compressed frequencies with amplitudes of the first 10 partials of the Tibetan trumpet. Table presented by Philippe Lalitte.

\begin{tabular}{lll}
\hline Rang & Frequence & Amplitude \\
\hline 1,0 & 1,0 & 88,0 \\
2,0 & 1,94 & 80,0 \\
3,0 & 2,9 & 94,0 \\
4,0 & 3,83 & 98,0 \\
5,0 & 4,74 & 114,0 \\
6,0 & 5,66 & 120,0 \\
7,0 & 6,63 & 117,0 \\
8,0 & 7,63 & 89,0 \\
9,0 & 8,42 & 89,0 \\
10,0 & 9,4 & 84,0 \\
\hline
\end{tabular}

In the synthesis, Murail stressed this inharmonic aspect and did a correction of $3 \%$ [Figure 1], because he wanted to get the original sonorities according to the same harmonies. Lalitte showed the first 40 partials of the analysis and the synthesis done by Murail as a harmonic "correction" (translated into notes) in the spectrum of the Tibetan trumpet in order to coherently enchain the harmonies in the piece [6]:

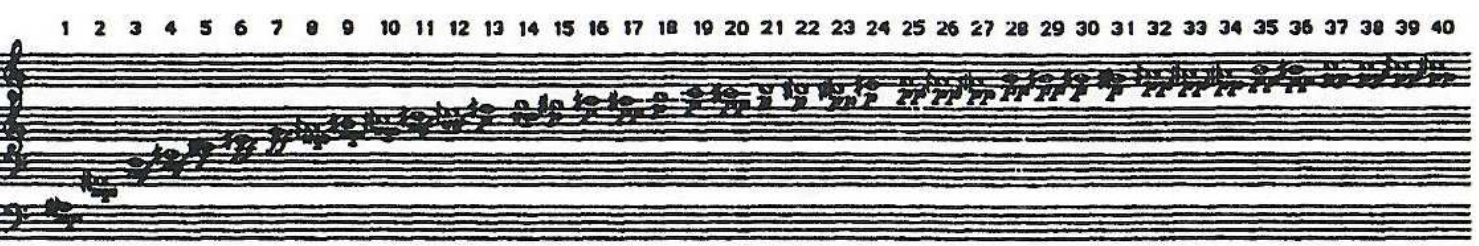

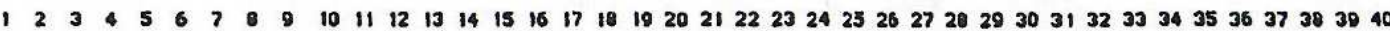

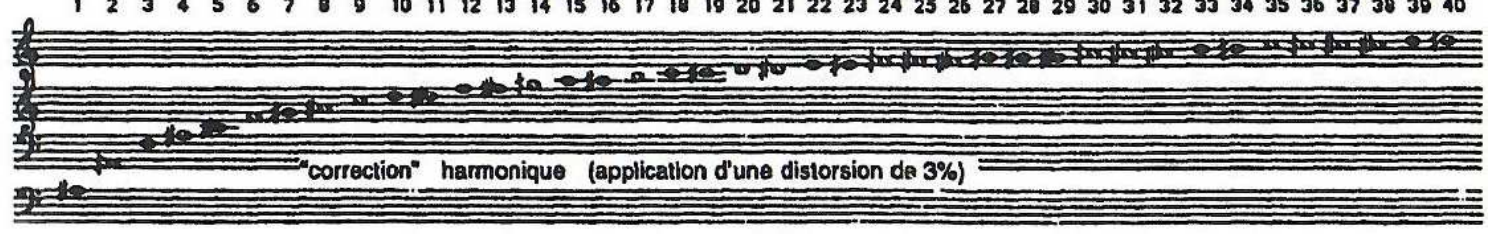

Figure 1. The first 40 partials of the analysis (first staff) and synthesis (second staff) of a Tibetan trumpet used in the work "L'Esprit des dunes".

The pitch, duration, and amplitude of each partial of the Mongol song were modified with a patch made in the music program Max, which consists of 40 oscillators [6].

\section{Objects}

The word "object" is often used in the electroacoustic 
music. It could refer to an already existing sound (including the noise) as musical, natural, ambient sound or to a synthesized sound obtained in the studio. Beginning with the Traité des objets musicaux (Paris, Éditions du Seuil 1966) by Pierre Schaeffer, the notions of "sound object" ("objet sonore") and "music object" ("objet musical") have accustomed in the language of composers who deal with electronics. Schaeffer spoke about "musique concrète" made of these objects. In the conception of Schaeffer sound objects (musical, natural, ambient sounds) become musical objects when they are intentionally used in a certain musical context. In this case they have an esthetic meaning.

By Murail one could speak about 'sound object', which refers to the acoustic existing aspect as the sound spectra that he analyzed, and about 'music object', which refers to the modeled and synthesized sound spectra, as the result of an artistic conception. With the given objects, the spectral ones, he created original and more complex instrumental or electronic objects. Here we can speak about the manufactured aspect characteristic for creating an object: it's about the material - the acoustic one -, which is shaped according to acoustic laws. As Thomas Hummel observes, there is a contradiction between the instrument and its acoustic law: the instrument.

"cannot just decomposed and recomposed its tones. There are always integer tones, which it plays, and it does not has thousand of adjusting screws of the electronic music. However, the instrument, in this sense imperfect, should «play» the laws of the acoustics, it should represent its acoustic nature in an analytic score". [7].

Murail calls a complex object a melodic fragment, a texture or a harmonic sequence [7]. The complex objects have a big quantity of information, which can be processed only with the computer.

\section{Technological Models}

We have already mentioned that Murail took the models for his works from the electronic music and translated them into the instrumental and orchestral scores. At the beginning of his career the electronic was not so advanced, one worked with magnetic tapes. In the 70s he tested the feedback loop with two tape recorders that he connected: he recorded the sounds on one tape recorder; the loop carried them to the second tape recorder; this fed the sounds back into the first recorder. All this generates a process, where the sounds are always copied and get degraded. In Mémoire/Érosion (197576) for horn and nine instruments he tried to simulate this feedback loop: the instruments have the role of the two recorders, repeating and transforming after a delay what the horn plays, until the initial sound of horn cannot be recognized. At that point the horn takes over the new element and this will be treated in the same way by the other instruments [4]. We can say that "memory" refers to the repetition and the "erosion" to the transformation - two notions that seem contradictory at the first view - that characterize Murail's compositions. Referring to this aspect,
Lukas Haselböck wrote: "The elements have to be recognizable and in the same time enough elastic to allow transformations, and in spite of this to preserve their identity". [8]. As Murail said, this piece was the beginning of a long search for models [4].

In Éthers (1978) for flute and five other instruments, the composer used other models from the electronic music, as echo, reverberation, phase shifting. One of the most important technological models used by the composer was the ring modulation: the input of two sounds gets the sum and the difference of their frequencies. He used it in this piece for the first time. The flute plays a pitch and sings in the same time another different pitch [4]. The resulting sounds are taken over by strings [9]. Murail could calculate later with the computer a lot of combination sounds resulting from the proceeding of ring modulation.

\section{Compositional Process}

The spectral music is the result of the inner sound analysis. The sound has a history, its evolution can be heard over time. Beside acoustics, psychoacoustics - the study of the sound hearing and perception - has an important role in the spectral music. According to Oliver Schneller, knowledge from acoustics (sound) and psychoacoustics (hearing) is applied in the spectral music through timbre and process orientated design [3].

As Hugues Dufourt observed, "the sound is an evolutionary process" [10]. It is known that any sound has an envelope, a curve that consists of attack, decay, sustain, release (ADSR). A sound changes its characteristics in the time. Murail wants to highlight these short changes through his works. The physical and phenomenological sound changes are put under microscope from the spectralists and extended over time in their compositions. Gerald Resch writes that events that last in fact only fractions of a second will be extremely stretched [11]. Thus, time becomes an important element of the composition. According to Andrea Siano, in the spectral music time is no more considered like "an external element imposed to the sound material, but on the contrary, it is treated like an element, which constitutes the sound itself" [12].

As we have seen, time is closed related on timbre. Although the timbre parameter of sound has been explored since the $20^{\text {th }}$ century, Felipe Pinto-d'Aguiar observed moments in some compositions of the past centuries, "where the standard musical development is temporally suspended and replaced by iterations or extreme prolongations of sonic material, which produce a focus on the vertical axis of sound, almost as if composers were attempting to scrutiny the musical fabric through a microscope, although only momentarily." [13]. In that cases the horizontality, the linearity (the melody) gives space to the verticality (the harmony) and the hearing is focused on the sonority.

The sound process is a model for Murail not only for the material, but also for the form. In this sense, Lukas Haselböck speaks about an organic growth and decay that 
come from the sound itself [14]. Jérôme Baillet speaks similary about an evolution of the tension over time. This evolution has the form of a sound envelope that contains a succession of transformation processes. According to him, Murail uses in the most of his pieces an envelope with the climax at the two-thirds of the total duration. This climax is like a break in the continuity of the work, while the middle is the calmest and most stable [15]. We have seen that since his first works, the process takes an important place in his way of composing. The process lends Murail's music continuity and drifts it away from the traditional musical forms. Although there is a periodicity in his music, some ideas return after a while, but they return transformed and this generates new ideas.

\section{The Work with the Computer}

The computer has an important role in the design process of Tristan Murail, in the conception, methodology, choise of material, modeling, form, and productivity.

The evolution of the technology and of the music informatics made the work of the composer easier. Concerning the methodology, at the beginning, he calculated "by hand". The possibility to calculate an amount of elements as a big number of partials, combination tones or the details of a complex sound, and the transcription of frequencies into notes (with the Program Open Music, developed at IRCAM) was a further step. The composer could concentrate on the musical aspect and choose from different combinations resulted from the same situation [5]. Before, when he calculated by hand, there were limits because of information amount. This influenced the aesthetics of the work as Murail said: "When you spend a long time for the calculation of very little material, you will stretch the using material, otherwise the project is not realizable. Therefore, there is a tendency to write pieces where the harmonic evolution is slow. Otherwise it would be too much work." [7]. The computer offers him an increasing of productivity. Even though some task could be automated this kind of productivity is not to be intended as the industry one [7]. As we have seen at the beginning the computer gives the composer new ideas and facilitates the sound manipulation and modeling.

\section{Conclusions}

Murail has musical talent, poetic imagination and in the same time technological skills and knowledge in music informatics, useful qualities for a composer and sound designer [16]. The point is that the computer is only a mean for him. As he says, in the creative process the hand work is present, intended as the traditional way of writing instrumental and orchestral scores. The creative impulse can be a poetic or musical idea. The computer gives him answers on certain questions [7] in the conception of his works.

Concerning the material, Murail has as starting point the given natural harmonic spectra, which he shapes regarding to acoustic laws. Both analysis and synthesis are based on numbers. The advanced the computer programs are, the accurate is the analysis and this fact changes the way of the score writing in the synthesis. The composer can see the life of the inner sound, how it evolves over time, with the help of computer programs. As a consequence, the natural acoustic material - the timbre will be obviously stressed separating, combining and moving continuously through its components, as harmonics, inharmonics, noises, distortions in the synthesis. The permanent moving and transforming from a component into other give his works the character of a process. The process determines the form. The form is treated as the material, after sound principles. Murail spoke about a parallelism between the structure of the sound and musical forms: "Both obey to the same principle of organization; there is a perfect adequacy between microcosms and macrocosms of the score" [15].

Taking his models from the electronic music Murail made complex and original instrumental objects, combing the artistic with the technological skills. His way of work and his work as a spectral composer involve him in the design process.

\section{References}

[1] Fineberg, Joshua. 2000. "Guide to the Basic Concepts and Techniques of Spectral Music", Contemporary Music Review, Vol. 19, Part 2, pp. 81-113.

[2] Rose, François. 1996. "Introduction to the Pitch organization of French Spectral Music", Perspectives of New Music, Vol. 34, No. 2, pp. 6-39.

[3] Schneller, Oliver. 2013. "KLANGFORSCHUNG UND KOMPOSITION. Einige Überlegungen zum spektralen Ansatz", Neue Zeitschrift für Musik, 02, pp. 26-32.

[4] Murail, Tristan. 2003. Seminar, Ostrova Days 2003 Report New, Ostrava: Music Institute and Festival Ostrova, pp. 97103.

[5] Michel, Pierre. 2002. "Entretien avec Tristan Murail", Tristan Murail, ed. by Peter Szendy, pp. 29-58. Paris: L'Harmattan.

[6] Lalitte, Philippe. 2002. "Le spectre d'une voix. Une analyse de L'Esprit des dunes", Tristan Murail, ed. by Peter Szendy, pp. 59-102. Paris: L'Harmattan.

[7] Hummel, Thomas. 2005. “...um mir das Vergehen der Zeit zu versüßen”, MusikTexte 107, pp. 1-7.

[8] Haselböck, Lukas. 2016. „Spektralmusik“, Lexikon Neue Musik, ed. by Jörn Peter Hiekel, Christian Utz, pp. 556-560. Kassel.

[9] Murail, Tristan. 2002. "Au fil des œvres“, Tristan Murail, ed. by Peter Szendy, pp. 103-52. Paris: L’Harmattan.

[10] Dufourt, Hugues. 2014. La musique spectrale. Une revolution épistémologique, Editions Delatour France.

[11] Resch, Gerald. 1999. "Natur Plus X. Die spektrale Musik des Groupe L'Itinéraire“, Österreichische Musikzeitschrift 54. Jahrgang, Heft 6, pp. 16-20. 
[12] Siano, Andrea. 2020. La trasformazione dell'oggetto sonoro dall'esperienza di Philippe Hurel alla realizzazione di Formalhaut". Tesi in composizione. Conservatorio di Musica Niccolò Piccini, Bari.

[13] Pinto-d'Aguiar, Felipe. 2020. "Musical OOPArts: early emergences of timbral objects", Proceedingsof the $2^{\text {nd }}$ International Conference on Timbre (Timbre 2020), 2-4 September 2020, Thesaloniki, Greece, pp. 1-4.

[14] Haselböck, Lukas. 2013. "Zur $<<$ Klabgfarbenlogik $>>$ bei Schönberg, Grisey und Murail", Klang und Wahrnehmung in der Musik des 20. und 21. Jahrhunderts, musiktheorien der gegenwart 6, Saarbrücken, pp. 137-162.

[15] Baillet, Jérôme. 2002. "L'esthétique musicale de Tristan Murail”, ed. by Peter Szendy, pp. 7-27. Paris: L'Harmattan.

[16] Zattra, Laura; Misdariis, Nicolas; Pecquet, Frank; Donin, Nicolas; Fierro, David 2018. "Analysis of Sound Design Practices [ASDP]. Research Methodology", Proceedings of the $22^{\text {nd }}$ Colloquium of Music Informatics (CIM) Machine Sounds, Sounds Machines, Udine, November 20-23, 2018, pp. 168-75. 